OPEN ACCESS

Edited by:

Amy Hai Yan Chan,

The University of Auckland,

New Zealand

Reviewed by:

Gianluca Serafini,

San Martino Hospital (IRCCS), Italy

Aleksandra Maria Rogowska,

Opole University, Poland

${ }^{*}$ Correspondence: Abdullah Seif Abdullah Al Miskry aabdullah@uaeu.ac.ae

${ }^{\dagger}$ These authors have contributed equally to this work

Specialty section:

This article was submitted to Health Psychology,

a section of the journal

Frontiers in Psychology

Received: 19 March 2021

Accepted: 12 July 2021

Published: 09 September 2021

Citation:

Al Miskry ASA, Hamid AAM and Darweesh AHM (2021) The Impact of COVID-19 Pandemic on University

Faculty, Staff, and Students and Coping Strategies Used During the

Lockdown in the United Arab Emirates. Front. Psychol. 12:682757. doi: 10.3389/fpsyg.2021.682757

\section{The Impact of COVID-19 Pandemic on University Faculty, Staff, and Students and Coping Strategies Used During the Lockdown in the United Arab Emirates}

\author{
Abdullah Seif Abdullah Al Miskry ${ }^{1 * \dagger}$, Abdalla A. M. Hamid ${ }^{2 \dagger}$ and \\ Abdel Hameed M. Darweesh ${ }^{1 \dagger}$
}

${ }^{1}$ Department of Cognitive Sciences, College of Humanities and Social Sciences, United Arab Emirates University, Al Ain, United Arab Emirates, ${ }^{2}$ Department of Clinical Psychology, College of Medicine and Health Sciences, United Arab Emirates University, Al Ain, United Arab Emirates

Introduction: The COVID-19 pandemic and the subsequent lockdown instigated serious mental health conditions. So far, the UAE data on mental health problems due to this pandemic outbreak is still scarce. The objective of this study was to identify the prevalent psychological difficulties experienced by university students, faculty members, and staff during COVID-19 lockdown and the coping strategies used.

Methods: A cross-sectional design was used to collect data from 737 participants using an online electronic survey. Participants included students, faculty members, and staff from universities in the UAE. The General Health Questionnaire (GHQ-12) was used to measure general distress, Penn State Worry Questionnaire (PSWQ-16) was used to measure worry, and the Coping Inventory for Stressful Situations (CISS-48) was administered to measure coping strategies used by participants during the COVID-19 pandemic lockdown. Data were collected during May to June 2020.

Results: The results indicated that $60.4 \%$ of students, $57.4 \%$ of the faculty members, and $52.3 \%$ of the staff experienced mild psychiatric problems. About $32.9 \%$ of students, $33.7 \%$ of the faculty members, and $25 \%$ of the staff experienced high levels of worry during the COVID-19 lockdown. Changes in eating patterns, worsening chronic health problems, change in sleep patterns, and concentration difficulties were reported. Furthermore, significant differences were observed in worry and coping strategies among participants. Women use more avoidance and emotion-focused coping compared to men.

Conclusion: It was concluded that COVID-19 lockdown has negatively impacted university faculty, staff, and students in terms of health behavior, psychological and physical health.

Keywords: COVID-19, university faculty members, university staff, students, distress, worry, coping 


\section{INTRODUCTION}

The new coronavirus (COVID-19) is a type of pneumonia first spotted in Wuhan, China (WHO, 2020a). The World Health Organization considers COVID-19 to be the sixth global public health concern (Guan et al., 2020). Its symptoms include cough, fever, muscle pain, sore throat, headache, loss of taste or smell, repeated shaking with chills, and difficulty breathing or shortness of breath (CDC, 2020). Clinical evidence indicates that older people and individuals with certain chronic illnesses such as lung disease, heart disease, and diabetes are at higher risk of getting infected with COVID-19 (CDC, 2020).

The COVID-19 pandemic has brought the greatest global challenge in this decade. The extent of the impact of this pandemic on global mental health and daily life is still mysterious. The unpredictable nature of the spread of this virus has brought great uncertainty within societies (Atchison et al., 2020; Verity et al., 2020), especially with the emergence of new variants of the virus (CDC, 2020). Researchers reported that about one-fifth of Iranians and almost a quarter of the Chinese population experienced severe to very severe levels of anxiety. Women were reported to experience more anxiety than men (Moghanibashi-Mansourieh, 2020; Wang et al., 2020).

Previous studies have shown increased distress associated with COVID-19 pandemic lockdown. For instance, some studies found that $22.8 \%$ of the participants experienced elevated stress (Yu et al., 2020). Furthermore, research revealed that two-thirds of the participants experienced psychological distress (Shahrour and Dardas, 2020). Moreover, another study demonstrated that about half of the participants experienced distress (Petzold et al., 2020).

In addition to the adverse effects of the disease, quarantining may also have a profound impact on mental health, such as fear of death, anger, and feeling of loneliness (Xiang et al., 2020). With more than 2.6 billion people living under some kind of quarantine, mental health cost is on the rise. The Lancet published a review of 24 studies documenting the distressing impact of quarantine on both public and healthcare workers. These impacts include depression, anxiety, anger, irritability, post-traumatic stress disorder (Brooks et al., 2020), distress, and worry (Kibbey et al., 2021). Other mental health problems incorporate low mood, insomnia, stress, and emotional exhaustion (World Economic Forum, 2020).

As mentioned above, worry is one of the major mental health issues related to the COVID-19 pandemic. Research has shown that worry is uniquely associated with anxious and depressive symptoms. Worry was found to be the dominant cognitive vulnerability factor that predicted increments in symptoms over time (Hong, 2007). One of the most stressful factors in worry is the unpredictability of the situation. In addition, the seriousness of the risk, and misinformation can heighten the sense of concern among the masses (Bao et al., 2020). Similarly, life challenges, such as the COVID-19 pandemic, and stress can trigger common mental health problems, such as anxiety, depression (Dar et al., 2017), and worry (Kibbey et al., 2021) that may need proper coping strategies to maintain individual mental well-being.

The worry induced by the COVID-19 pandemic is highly associated with psychological distress and may impact the coping strategies used by individuals (Rushabh, 2020). Regarding pandemic-related coping behavior, research has indicated that younger adults utilized a variety of coping strategies, such as avoidance and emotion-focused coping in an effort to control worry, compared to old adults (Hunt et al., 2003). In addition, age was found to be a significant factor in mental health as research has reported that COVID-19 pandemic quarantine affected people aged 21-40 years and above, in terms of their mental health condition (Ahmed et al., 2020). With regard to gender, research literature indicates significant gender differences in distress (Abu-Kaf et al., 2020; Bilodeau et al., 2020; Hamid and Abdullah, 2020; Olaseni et al., 2020), worry (Barahmand, 2008; Zlomke and Hahn, 2010; Bottesi et al., 2018; Domotor et al., 2019; Fu et al., 2020), and coping (Gemmell et al., 2016; Flannery et al., 2018; Martínez et al., 2019; Wang et al., 2020).

Literature reported that distress was associated with marital status during previous pandemic diseases (Babore et al., 2020). However, literature regarding the influence of marital status on distress during the outbreak of COVID-19 is inconsistent. Some studies argued that marital status was associated with distressrelated insomnia and worry about family members; in contrast, others found no significant association (Fu et al., 2020; Li et al., 2020). For example, marital status was not a risk factor in psychological distress indicators, such as anxiety (Badahdah et al., 2020) and perceived distress (Babore et al., 2020).

Little is known about the psychological impact of COVID19 , and the ways faculty members, staff, and students use to cope with this quarantine in the UAE settings. However, research has uncovered that COVID-19 is possibly linked to worry (WHO, 2020b), anxiety (Kibbey et al., 2021), stress, and negative emotional reaction (CDC, 2020). Alcohol and other substances are also widely used by people in crisis to reduce negative emotions, distress, anxiety, or depression (Chodkiewicz et al., 2020). Therefore, this study explores the psychological impact of COVID-19 on university faculty members, staff, and students, and also the coping strategies used during the lockdown. The aim of this study was 3-fold: (1) to identify the prevalence of psychological difficulties experienced by faculty members, staff, and students during the COVID-19 lockdown; (2) to investigate the behavioral changes among participants during the COVID-19 pandemic lockdown; and (3) to identify the differences in worry, distress, and the coping strategies used during the COVID-19 lockdown with regard to gender, age groups, marital status, and categories of participants (faculty members, staff, and students). Based on the objectives of the study, the following hypotheses are stated: (1) psychological difficulties will be highly prevalent among faculty members, staff, and students during the COVID19 lockdown; (2) participants will experience some behavioral changes during the COVID-19 pandemic lockdown; and (3) participant are expected to differ in worry, distress, and coping strategies with regard to demographic characteristics.

\section{MATERIALS AND METHODS}

\section{Sample}

The sample is composed of 737 participants: $60.7 \%(n=447)$ university students, $27.4 \%(n=202)$ faculty members, and $11.9 \%(n=88)$ staff selected through the convenience sampling 
TABLE 1 | Description of the demographic characteristics of the study sample.

\begin{tabular}{|c|c|c|c|c|c|c|c|}
\hline \multicolumn{2}{|l|}{ Variable } & \multicolumn{2}{|c|}{ Students } & \multicolumn{2}{|c|}{ Faculty } & \multicolumn{2}{|c|}{ Staff } \\
\hline & & $n$ & $\%$ & $n$ & $\%$ & $n$ & $\%$ \\
\hline \multirow[t]{2}{*}{ Gender } & Male & 42 & 9.4 & 132 & 56.3 & 28 & 31.8 \\
\hline & Female & 405 & 90.6 & 70 & 34.7 & 60 & 68.2 \\
\hline \multirow[t]{3}{*}{ Marital status } & Married & 18 & 4 & 148 & 73.3 & 48 & 54.5 \\
\hline & Single & 429 & 96 & 18 & 8.9 & 34 & 38.6 \\
\hline & $\begin{array}{l}\text { Married } \\
\text { (family is away) }\end{array}$ & 0 & 0 & 36 & 17.8 & 6 & 6.8 \\
\hline \multirow[t]{6}{*}{ Age Group } & $18<$ & 114 & 25.5 & 0 & 0 & 0 & 0 \\
\hline & 19-22 & 294 & 65.8 & 0 & 0 & 0 & 0 \\
\hline & 23-29 & 39 & 8.7 & 0 & 0 & 0 & 0 \\
\hline & 30-39 & 0 & 0 & 12 & 5.9 & 48 & 54.5 \\
\hline & $40-49$ & 0 & 0 & 92 & 45.5 & 32 & 36.4 \\
\hline & $50>$ & 0 & 0 & 98 & 48.5 & 8 & 9.1 \\
\hline
\end{tabular}

$n=737$.

method. The samples were selected from three universities (one public and two private) in Al Ain city, the emirate of Abu Dhabi, UAE. The common languages of the participants are Arabic and English. About $15.5 \%(n=114)$ of the participants were aged 18 years and below, 39.9\% $(n=249)$ aged $19-22$ years, $5.3 \%$ $(n=39)$ aged $23-29$ years, $8.1 \%(n=60)$ aged $30-39$ years, $16.8 \%(n=124)$ aged $40-49$ years, and $14.4 \%(n=105)$ were 50 years and above. Around $72.6 \%(n=535)$ of the participants were females, whereas $27.4 \%(n=202)$ were males. Regarding marital status, 29\% $(n=214)$ were married, and their families live with them in the UAE; $65.3 \%(n=481)$ single, and $5.7 \%$ ( $n=42$ ) married, but their families live outside the UAE. For more description of the sample characteristics, see Table 1. The inclusion criteria for students in this study was to be enrolled during 2020/2021 academic year and for faculty and staff to be active employees in the universities. The participants with recent psychiatric diagnoses were excluded.

\section{Measures}

\section{Demographic Information}

Participants were requested to indicate their age, sex, marital status, and if they were faculty members, staff, or students. The participants were also asked to respond to the General Health Questionnaire (GHQ-12), the Penn State Worry Questionnaire (PSWQ), the Coping Inventory for Stressful Situations (CISS) and three other questions (worry about own health and health of their loved ones, behavior and health changes, and increased use of substances).

\section{The General Health Questionnaire}

The Arabic and English versions were used in the study. The GHQ-12 is composed of 12 items used to measure general distress (Goldberg and Williams, 1991). There are two methods of scoring the GHQ: one is the Likert-type scaling method (0, 1 , $2,3)$, which is used in survey research, and the other is the GHQ scoring method $(0,0,1,1)$, which is used to identify individuals with non-psychotic psychiatric disorders (Sallow et al., 2003). Both methods were used in this study, a cut-off of 6 was used with the GHQ scoring method to identify the percentages of non-psychotic psychiatric disorders (Endsley et al., 2017). The Arabic version was validated by Hamid and Musa (2010). The Cronbach's $\alpha$ reliability in the Arab sample was 0.94 . The Cronbach's $\alpha$ in the current study was $0.81(M=18.22$; SD $=5.25)$.

\section{The Penn State Worry Questionnaire}

The PSWQ is a self-report measure assessing clinically significant worry (Meyer et al., 1990). It consists of 16 items rated on a 5-point Likert-type scale, ranging from $1=$ not at all typical of me to $5=$ very typical of me (sample item: "I am always worrying about something"), depending on whether the item is worded positively or negatively. The cutoff point of 53 was used in this based on the literature on the Penn State Worry Questionnaire (Park et al., 2014). Adequate test-retest reliability of 0.74 was reported (VivWuthrich et al., 2014). The PSWQ was translated independently by three psychology professors following International Test Commission Guidelines for Translating and Adapting Tests (ITC, 2017), using a forwardbackward translation method. The three professors are native Arabic speakers who completed their graduate studies in the Western universities. The Arabic version was given to a specialist in translation studies who translated it back into English to ensure semantic equivalence. In the current study, the Cronbach's $\alpha$ reliability was $0.85(M=48.26$; $\mathrm{SD}=8.13)$.

\section{The Coping Inventory for Stressful Situations}

The CISS comprises 48 items rated in a 5-point Likert type scale (Endler and Parker, 1994). Score 1 indicates not all engaged in the activity, and score 5 indicates very much engaged in the activity. The items are distributed in three major factors namely, taskfocused, emotion-focused, and avoidance coping. Each factor consists of 16 items. Avoidance is further divided into two factors. These are social diversion coping and distraction coping (Cosway et al., 2000; Rafnsson et al., 2006). In the present study, avoidance was used as one factor. The Arabic version of this measure was already used in previous studies (Hamid and Abdullah, 2017; Hamid and Musa, 2017). The Cronbach's $\alpha$ reliabilities of CISS in two UAE samples were 0.74 (Hamid and Abdullah, 2017) and 0.88 (Hamid and Musa, 2017), respectively. In the current study, the Cronbach's $\alpha$ reliability of CISS is $0.86(M=158.54$; $\mathrm{SD}=$ 21.71). With regard to the reliability of CISS dimensions, Choi et al. (2017) reported the alpha of 0.92 for task-focused, 0.88 for emotion-focused, and 0.86 for avoidance. For the current study, the Cronbach's $\alpha$-values for task-focused coping was 0.86 , emotion-focused coping was 0.84 , and for avoidance was 0.82 .

\section{Procedure}

A link of a survey composed of the online questionnaires and a section of demographic data (age, gender, categories, and marital status) was e-mailed to the participants after the Ethical approval from the Social Sciences Research Ethics Committee was granted (Ref No: ERS_2020_6114). The survey was e-mailed to participants during the COVID-19 lockdown from May to 
June 2020. The first page of the survey contained a consent form requesting the agreement of participants before responding to the questionnaire.

The objectives of the study and instructions on how the questionnaires would be responded to were clearly explained at the beginning of each questionnaire. They were informed of the voluntary nature of participation and the confidentiality policy. They were also informed that the data provided would only be used for research purposes and that their private information will never be revealed. Furthermore, they were also informed that they could withdraw from the study at any stage.

\section{Data Analysis}

The Statistical Package for Social Science (IBM SPSS, v26; IBM Corp., Armonk, NY, USA) was used to analyze the data. Skewness and kurtosis values were computed to test the normality of univariate distribution of the data. Skewness and kurtosis values were within the range of normality $( \pm 1.96)$ (Gravetter and Wallnau, 2014). Following the normality tests, descriptive analyses were performed to identify the levels of psychological difficulties and behavioral changes experienced by participants. The $t$-test and ANOVA were administered to examine group differences in distress, worry, and coping.

\section{RESULTS}

\section{The Prevalence of Mild Risk of Psychiatric Problems and Worry Among Faculty Members, Staff, and Students}

Based on the cutoff point of 6 , the results of the GHQ-12 indicated that $57.4 \%$ of the faculty members, $52.3 \%$ of the staff, and $60.4 \%$ of the students experienced mild risk of psychiatric problems. Regarding gender, $51.5 \%$ of the males and $61.3 \%$ of the females experienced mild risk of psychiatric problem. Concerning marital status, $57.7 \%$ of the married, $58.4 \%$ of the singles, and $66.7 \%$ of the married participants whose families are not in the UAE experienced substantial psychological difficulties.

With regard to worry, the results indicated that $33.7 \%$ of the faculty members experienced high level of worry during the COVID-19 lockdown compared to $25.0 \%$ of the staff and $32.9 \%$ of students as shown in Table 2. As for gender, $24.3 \%$ of the male participants and $35.1 \%$ the females experienced high levels of worry.

Regarding marital status, $22.4 \%$ of the married, $33.9 \%$ of the single, and $61.9 \%$ of the married whose families are not in the UAE experienced high levels of worry (see Table 3 ).

The researchers used three questions to measure health worry, behavior, and health changes of participants, and increased use of some substances. The first question measured worry about own health and worrying about the health of loved ones among participants. The results illustrated that about $18.5 \%$ of the participants reported worrying about their own health, whereas $81.5 \%$ reported worrying about the health of their loved ones (see Table 4). The majority reported worry about the health of their loved ones.
TABLE 2 | The prevalence of mild risk of psychiatric problems and worry among faculty members, staff, and students during the COVID-19 pandemic.

\begin{tabular}{|c|c|c|c|c|c|c|}
\hline \multirow{3}{*}{$\begin{array}{l}\text { Variables } \\
\text { GHQ-12 }\end{array}$} & \multicolumn{6}{|c|}{ Category } \\
\hline & \multicolumn{2}{|c|}{ Faculty members } & \multicolumn{2}{|c|}{ Staff } & \multicolumn{2}{|c|}{ Students } \\
\hline & $N$ & $\%$ & $n$ & $\%$ & $n$ & $\%$ \\
\hline $\begin{array}{l}\text { No risk of psychiatric } \\
\text { problems }\end{array}$ & 86 & 42.6 & 42 & 47.7 & 177 & 39.6 \\
\hline $\begin{array}{l}\text { Mild risk of psychiatric } \\
\text { problems }\end{array}$ & 116 & 57.4 & 46 & 52.3 & 270 & 60.4 \\
\hline \multicolumn{7}{|l|}{ Penn-State Worry } \\
\hline Low worry & 134 & 66.3 & 66 & 75.0 & 300 & 67.1 \\
\hline High worry & 68 & 33.7 & 22 & 25.0 & 147 & 32.9 \\
\hline
\end{tabular}

${ }^{*}$ Mild risk of psychiatric problems $=$ Scored 6/12 on GHQ-12. $\chi 2(2, N=737)=2.17$, $p=0.339$.

${ }^{*}$ The cutoff point for worry is 53/80. $\times 2(2, N=737)=2.39, p=0.303$.

TABLE 3 | The prevalence of mild risk of psychiatric problems and worry across marital status during the COVID-19 pandemic.

\begin{tabular}{|c|c|c|c|c|c|c|}
\hline \multirow{3}{*}{$\begin{array}{l}\text { Variables } \\
\text { GHQ-12 }\end{array}$} & \multicolumn{6}{|c|}{ Marital status } \\
\hline & \multicolumn{2}{|c|}{ Married } & \multicolumn{2}{|c|}{ Single } & \multicolumn{2}{|c|}{$\begin{array}{l}\text { Married but away } \\
\text { from family }\end{array}$} \\
\hline & $n$ & $\%$ & $n$ & $\%$ & $n$ & $\%$ \\
\hline $\begin{array}{l}\text { No risk of } \\
\text { psychiatric problems }\end{array}$ & 91 & 42.5 & 200 & 41.6 & 14 & 33.3 \\
\hline $\begin{array}{l}\text { Mild risk of } \\
\text { psychiatric problems }\end{array}$ & 123 & 57.5 & 281 & 58.4 & 28 & 66.7 \\
\hline \multicolumn{7}{|c|}{ Penn State Worry Questionnaire } \\
\hline Low worry & 166 & 77.6 & 318 & 66.1 & 16 & 38.1 \\
\hline High worry & 48 & 22.4 & 163 & 33.9 & 26 & 61.9 \\
\hline
\end{tabular}

${ }^{*}$ Mild risk of psychiatric problems $=$ Scored 6/12 on GHQ-12. $\times 2(2, N=737)=1.244$, $p=0.537$.

${ }^{*}$ The cutoff point for worry is 53/80. $\left.\times 2(2, N=737)=26.98, p=0.00\right)$.

The second question assessed about behavior and health changes of participants during the COVID-19 lockdown. The results indicated that $22.5 \%$ of the participants reported changes in eating patterns, $18.3 \%$ reported worsening chronic health problems, $19.5 \%$ experienced changes in sleep patterns, and $18 \%$ reported concentration difficulties. Furthermore, 11.8\% of participants reported deterioration in mental health status. With regard to the third question, the results demonstrate that consumption of tobacco, alcohol, and coffee among participants increased during the COVID-19 pandemic lockdown (see Table 4).

\section{Gender Differences in Distress, Worry, and Coping}

The result indicated significant gender differences in distress, worry, avoidance, and emotion-focused coping. Female participants consistently scored higher than males in these variables. There were no significant differences in task-focused coping (see Table 5). 
TABLE 4 | Participants' responses to three questions measuring health worry, behavior, and health changes, and increased use of some substances.

\begin{tabular}{lcc}
\hline Questions & $\boldsymbol{n}$ & $\%$ \\
\hline 1. Worry about own health vs. worry & about health of their loved ones \\
Own health & 136 & 18.5 \\
Health of loved ones & 601 & 81.5 \\
2. Behavior and health changes & & \\
Change in eating patterns & 66 & 22.5 \\
Difficulty sleeping & 144 & 19.5 \\
Difficulty concentrating & 133 & 18.5 \\
Worsening chronic physical health problem & 135 & 18.3 \\
Worsening mental health & 87 & 11.8 \\
Other problems & 72 & 9.8 \\
3. Increased use of substances & & \\
Alcohol & 92 & 12.5 \\
Tobacco & 96 & 13 \\
Coffee & 189 & 25.6 \\
Other drugs & 65 & 8.8 \\
No changes & 136 & 18.9 \\
Not applicable & 156 & 22.2 \\
\hline & & \\
\hline
\end{tabular}

TABLE 5 | Gender differences in distress, worry, and coping.

\begin{tabular}{|c|c|c|c|c|c|c|c|c|}
\hline \multirow[t]{2}{*}{ Variable } & \multicolumn{2}{|c|}{ Male } & \multicolumn{2}{|c|}{ Female } & \multirow[t]{2}{*}{$t$} & \multirow[t]{2}{*}{$d f$} & \multirow[t]{2}{*}{$p$} & \multirow[t]{2}{*}{ Cohen's $d$} \\
\hline & $M$ & $S D$ & $M$ & $S D$ & & & & \\
\hline Distress & 5.41 & 3.31 & 5.93 & 2.2 & -2.42 & 735 & 0.020 & 0.258 \\
\hline Worry & 46.75 & 8.02 & 48.83 & 8.10 & -3.12 & 735 & 0.002 & 0.185 \\
\hline Task & 56.33 & 9.69 & 57.79 & 10.25 & -1.76 & 735 & 0.08 & 0.146 \\
\hline Emotion & 47.53 & 11.00 & 51.52 & 10.60 & -4.51 & 735 & 0.000 & 0.369 \\
\hline Avoidance & 49.11 & 12.12 & 51.34 & 10.32 & -2.49 & 735 & 0.013 & 0.198 \\
\hline
\end{tabular}

\section{Differences in Distress, Worry, and Coping Between Faculty Members, Staff, and Students}

The ANOVA results showed significant differences in distress between faculty members, staff, and students $\left[F_{(2,734)}=5.471\right.$, $\left.p<0.01, \eta^{2}=0.02\right]$. The post hoc results indicated that faculty members and students experienced more distress compared to staff $(\mathrm{MD}=1.51, p<0.05 ; \mathrm{MD}=2.00, p<0.01$, respectively). However, no significant differences were found in worry. As for coping, the results indicated significant differences in taskfocused and emotion-focused coping $\left[F_{(2,736)}=3.564, p<0.05\right.$, $\eta^{2}=0.010 ; F_{(2,736)}=3.097, p<0.05, \eta^{2}=0.008$, respectively]. There was no significant difference in avoidance coping.

\section{Differences in Distress, Worry, and Coping Across Marital Status}

The ANOVA results showed significant differences in distress, worry, emotion-focused, and avoidance coping between single, married with families staying in the UAE, and those who are married but their families are outside the UAE.
However, Eta-squared values suggest that these differences are small (see Table 6).

\section{Differences in Distress, Worry, and Coping Across Age Groups}

The ANOVA results showed significant differences in distress and worry across age groups (see Table 7). With regard to distress, the Least Significant Difference (LSD) post hoc results showed that the younger group (18 and below) experienced more distress compared to the age groups of $19-22$ and $40-49$ years $(\mathrm{MD}=$ $-1.70, p<0.01 ; \mathrm{MD}=-1.65, p<0.05$, respectively). Those aged 19-22 years old experienced less distress compared to the age groups of $30-39$ and 50 and above $(\mathrm{MD}=2.25, p<0.01$ and $\mathrm{MD}$ $=2.44, p<0.001$, respectively). The age group of 23-29 reported less distress than the age groups of 30-39 and 50 and above (MD $=2.31, p<0.05$ and $\mathrm{MD}=2.49, p<0.05$, respectively).

With regard to worry, ANOVA results showed significant group differences in worry across age groups (see Table 7 ). The LSD post hoc results showed that the age group of 18 and below reported less worry compared to the age group of 19-22 (MD = $-1.99, p<0.01)$. The age group of $19-22$ reported more worry compared to those in the age group of 23-29 $(\mathrm{MD}=-3.69$, $p<0.01$ ), whereas the age group of 23-29 reported less worry compared to the age groups of 30-39 and 50 and above (MD = 4.07, $p<0.05$ and $\mathrm{MD}=3.78, p<0.05$, respectively).

The ANOVA results also showed significant differences between age groups in the use of task-focused, emotion-focused, and avoidance coping, $\left[F_{(5,731)}=5.014, p<0.001, \eta^{2}=0.033\right.$; $F_{(5,731)}=7.402, p<0.001, \eta^{2}=0.048$; and $F_{(5,731)}=5.519, p<$ $0.001, \eta^{2}=0.036$, respectively] (see Table 7).

With regard to task-focused coping, the LSD post hoc results showed that the younger group (18 and below) used more taskoriented coping compared to the age groups of 19-22, 23-29, 3039 , and 40-49 years $(\mathrm{MD}=2.99, p<0.01 ; \mathrm{MD}=3.76, p<0.05$; $\mathrm{MD}=5.98, p<0.001$; and $\mathrm{MD}=5.46, p<0.001$, respectively).

About emotion-focused coping, the age group of 50 and above used less emotion-focused coping compared to the age groups of 18 and below, 19-22, 23-29, and 30-39 years $(\mathrm{MD}=7.38, p<$ $0.001 ; \mathrm{MD}=5.66, p<0.001 ; \mathrm{MD}=6.75, p<0.01 ;$ and $\mathrm{MD}=$ $4.88, p<0.01$, respectively).

As for avoidance coping, the results indicated that the younger age groups used more avoidance coping compared to the older groups. The age group of 18 and below used more avoidance coping compared to the age groups of 23-29 years $(\mathrm{MD}=7.74$, $p<0.001)$ and the age group of 50 and above $(\mathrm{MD}=3.44, p$ $<0.01)$. The age group of 23-29 used more avoidance coping compared to the age groups of $30-39(\mathrm{MD}=6.53, p<0.01)$, and the age group of 40-49 used more avoidance coping than the age group of 50 and above $(\mathrm{MD}=5.02, p<0.001)$.

\section{DISCUSSION}

The findings of the study suggest that about $57.7 \%$ of the faculty members, $52.3 \%$ of the staff, and $32.9 \%$ of the students scored 6/12 or more on the GHQ-12. Thus, the first hypothesis, which posited that psychological difficulties would be highly 
TABLE 6 | ANOVA results of differences in distress, worry, and coping across marital status.

\begin{tabular}{|c|c|c|c|c|c|c|c|c|}
\hline Variables & & $n$ & $M$ & $S D$ & $d f$ & $\boldsymbol{F}$ & $p$ & $\eta^{2}$ \\
\hline \multirow[t]{3}{*}{ Distress } & Married (family in UAE) & 214 & 5.79 & 3.59 & 2,736 & 6.526 & 0.002 & 0.017 \\
\hline & Single & 481 & 5.67 & 1.85 & & & & \\
\hline & Married (family is way) & 42 & 7.14 & 2.95 & & & & \\
\hline \multirow[t]{3}{*}{ Worry } & Married (family in UAE) & 214 & 46.92 & 7.67 & 2,736 & 7.667 & 0.001 & 0.020 \\
\hline & Single & 481 & 48.53 & 8.42 & & & & \\
\hline & Married (family is away) & 42 & 51.95 & 5.08 & & & & \\
\hline \multirow[t]{3}{*}{ Task } & Married (family in UAE) & 214 & 55.73 & 9.76 & 2,736 & 4.337 & 0.013 & 0.012 \\
\hline & Single & 481 & 58.155 & 10.32 & & & & \\
\hline & Married (family is away) & 42 & 57.05 & 7.77 & & & & \\
\hline \multirow[t]{3}{*}{ Emotion } & Married (family in UAE) & 214 & 48.25 & 10.3 & 2,736 & 10.407 & 0.000 & 0.028 \\
\hline & Single & 481 & 50.91 & 10.88 & & & & \\
\hline & Married (family is away) & 42 & 55.90 & 10.76 & & & & \\
\hline \multirow[t]{3}{*}{ Avoidance } & Married (family in UAE) & 214 & 50.48 & 10.98 & 2,736 & 6.634 & 0.001 & 0.018 \\
\hline & Single & 481 & 50.33 & 10.80 & & & & \\
\hline & Married (family is away) & 42 & 56.62 & 9.76 & & & & \\
\hline
\end{tabular}

TABLE 7 | ANOVA results of distress, worry, and coping differences across age groups.

\begin{tabular}{|c|c|c|c|c|c|c|c|c|}
\hline Variable & Age group & $n$ & $M$ & $S D$ & $\boldsymbol{F}$ & $d f$ & Sig. & $\eta^{2}$ \\
\hline \multirow[t]{6}{*}{ Distress } & 18 \& below & 114 & 17.32 & 2.78 & 5.923 & 5,731 & 0.000 & 0.039 \\
\hline & 19-22 & 294 & 19.02 & 3.46 & & & & \\
\hline & $23-29$ & 39 & 19.08 & 3.40 & & & & \\
\hline & 30-39 & 60 & 16.77 & 6.71 & & & & \\
\hline & $40-49$ & 124 & 18.97 & 7.26 & & & & \\
\hline & $50 \&$ above & 106 & 16.58 & 7.41 & & & & \\
\hline \multirow[t]{6}{*}{ Worry } & 18 \& below & 114 & 49.50 & 7.23 & 2.475 & 5,731 & 0.031 & 0.017 \\
\hline & 19-22 & 294 & 47.62 & 8.56 & & & & \\
\hline & 23-29 & 39 & 51.31 & 9.37 & & & & \\
\hline & 30-39 & 60 & 47.23 & 7.71 & & & & \\
\hline & $40-49$ & 124 & 48.77 & 6.36 & & & & \\
\hline & $50 \&$ above & 106 & 47.53 & 9.03 & & & & \\
\hline \multirow[t]{6}{*}{ Task } & 18 \& below & 114 & 60.45 & 9.30 & 5.014 & 5,731 & 0.000 & 0.033 \\
\hline & 19-22 & 294 & 57.46 & 10.70 & & & & \\
\hline & 23-29 & 39 & 56.69 & 10.21 & & & & \\
\hline & $30-39$ & 60 & 54.47 & 8.93 & & & & \\
\hline & $40-49$ & 124 & 54.98 & 8.94 & & & & \\
\hline & $50 \&$ above & 106 & 58.62 & 9.96 & & & & \\
\hline \multirow[t]{6}{*}{ Emotion } & 18 \& below & 114 & 52.39 & 10.50 & 7.402 & 5,731 & 0.000 & 0.048 \\
\hline & $19-22$ & 294 & 50.67 & 10.83 & & & & \\
\hline & 23-29 & 39 & 51.77 & 12.60 & & & & \\
\hline & 30-39 & 60 & 49.90 & 9.00 & & & & \\
\hline & $40-49$ & 124 & 52.48 & 9.25 & & & & \\
\hline & $50 \&$ above & 106 & 45.02 & 11.63 & & & & \\
\hline \multirow[t]{6}{*}{ Avoidance } & 18 \& below & 114 & 51.95 & 10.72 & 5.519 & 5,731 & 0.000 & 0.036 \\
\hline & 19-22 & 294 & 50.63 & 11.26 & & & & \\
\hline & 23-29 & 39 & 44.54 & 10.60 & & & & \\
\hline & 30-39 & 60 & 51.07 & 6.70 & & & & \\
\hline & 40-49 & 124 & 53.53 & 9.51 & & & & \\
\hline & 50 \& above & 106 & 48.51 & 12.27 & & & & \\
\hline
\end{tabular}


prevalent among participants during the COVID-19 lockdown, is supported. This result indicates a high prevalence of mild risk of psychiatric problems among participants during the COVID-19 lockdown. These findings are consistent with Petzold et al. (2020) findings that found over $50 \%$ of the participants expressing elevated levels of psychological distress related to the COVID-19 pandemic. Similarly, Son et al. (2020) found that $71 \%$ of students reported heightened stress and anxiety related to the COVID-19 pandemic. Furthermore, Wang et al. (2020) reported moderateto-severe psychological difficulties among the general population in China during the initial stage of the COVID-19 pandemic.

The high prevalence of psychological difficulties in the present study was further supported by the responses of participants to a question on mental health status in which over $11.8 \%$ of them perceived deterioration in their mental health status. This result is supported by the findings of Lyons et al. (2020) who reported a high percentage of mental well-being deterioration among Australian students during the COVID-19 pandemic.

However, the findings of the current study suggest that participants may not be fully aware of the real impact of COVID19 lockdown on their mental health as their response to the direct question about the deterioration of mental health was not consistent with the results of the GHQ-12. Nonetheless, more than $18 \%$ of the participants reported worsening chronic physical health.

The age group of 19-22 experienced lower levels of distress compared to the other age groups except for the age group of 18 and below. The youngest group (18 and below) experienced a higher level of distress that could be due to being in their first year at the University where they had to deal with both the challenges of being junior students and the demands of COVID-19 lockdown. These findings are in line with previous studies by Shahrour and Dardas (2020) and Alkhamees et al. (2020).

With regard to worry, the findings suggest that more than $33 \%$ of the faculty members, $25 \%$ of staff, and $32.9 \%$ of students experienced a high level of worry during the pandemic lockdown. They were more worried about the health of their loved ones (81.5\%) than about their own health $(18.5 \%)$. This result is consistent with the previous studies that found high levels of fear and worry among individuals about the health of their loved ones compared to their own health (Son et al., 2020).

The second hypothesis postulated that participants would experience some behavioral changes during the COVID-19 pandemic lockdown. The findings suggest that the most affected behaviors were coffee consumption, eating patterns, sleeping difficulties, concentration difficulties, increased use of tobacco, and alcohol consumption. Hence, the second hypothesis of the study is supported. These findings are consistent with the previous studies that reported a higher percentage of concentration difficulties and disruptions in sleeping patterns among students (e.g., Son et al., 2020). The findings are also consistent with a previous study, which reported $14 \%$ increase in alcohol consumption during COVID-19 "Lockdown" in Poland (Chodkiewicz et al., 2020). Likewise, Czeisler et al. (2020) reported that $13.3 \%$ of the participants experienced increased substance use during COVID-19 lockdown. However, only
$18.9 \%$ of the participants in our study reported no changes in their behavior.

The third hypothesis suggests that participants would differ in worry, distress, and coping strategies with regard to demographic characteristics. The results supported this hypothesis. It is clear from the findings that faculty members and students experienced greater levels of distress compared to staff. This may be due to the demanding nature of online teaching and the lack of face-to-face interaction.

The findings suggest that women use more avoidance and emotion-focused coping during COVID-19 lockdown than do men. This indicates that men may be more capable of adapting to the demands of the COVID-19 lockdown contrary to what was suggested by previous research (Umucu and Lee, 2020). Consistent with the previous studies (Abu-Kaf et al., 2020; Bilodeau et al., 2020), we found that women experience more distress than did men. The greater level of worry experienced by women in this study compared to men is similar to that found by Bottesi et al. (2018) and Domotor et al. (2019). This result is inconsistent with the findings of Zlomke and Hahn (2010) where men were found to experience more worry compared to women.

With regard to marital status, the findings denoted that the single participants used more task-focused coping compared to the married ones. Those who are married but their families are outside the UAE reported more distress, worry, and avoidance coping compared to singles and married whose families are in the UAE. These results are inconsistent with the findings that unmarried individuals were more likely to experience heightened distress compared to the married participants (Yu et al., 2020).

In terms of age groups, those aged 22-29 reported more distress and worry compared to the other age groups. The older group appeared to use more emotion-focused and avoidance coping in dealing with distress and worry related to the COVID19 lockdown, whereas the younger age group (18 and below) seemed to use more task-focused coping.

\section{CONCLUSION}

The COVID-19 lockdown has negatively impacted the psychological and physical health of faculty members, staff, and university students. More than $57 \%$ of faculty members, $52 \%$ of staff, and $60 \%$ of students experienced mild risk of psychiatric problems. Females seem to be more susceptible to these problems. Special attention needs to be directed toward married individuals whose families are not living with them during the pandemic lockdown as they are most prone to mental health. Online counseling might be useful to help them deal with the psychological distress they experience. In addition, equipping them with effective coping skills may enhance their resilience in such situations. Furthermore, more reliable and up-to-date information about the COVID-19 prevention could reduce the fear and distress they experience. The COVID-19 lockdown increased the use of the substance, such as tobacco, alcohol, and coffee. Females seem to use more avoidance and emotion-focused coping in dealing with the demands of COVID-19 lockdown. Those aged 40-49 also seem to use 
more emotion-focused and avoidance coping. In addition, participants seemed to worry more about the health of their loved ones than about their own health. This population may be resurveyed at the end of the pandemic lockdown to examine the long-term psychological impact of COVID-19 among the university communities. Overall, the COVID-19 has posed a very high demand, especially on the faculty members and university students. This is evident in the elevated psychological difficulties such as worry and distress that necessitate behavioral changes aimed at managing this situation.

\section{LIMITATIONS}

One limitation of the current study is the use of an online survey in data collection. Online surveys are associated with low response rates that may negatively affect the generalizability of findings (Sivo et al., 2006; Mulvany et al., 2019). However, this method was the only available means to collect data from participants during the COVID-19 lockdown. Further, the current study is exploratory and cross-sectional in nature. Hence, advanced designs may be appropriate to explore causal associations among the study variables. Furthermore, a convenient sampling method was used in this study, which may not be appropriate to draw a representative sample of the

\section{REFERENCES}

Abu-Kaf, S., Nakash, O., Hayat, T., and Cohen, M. (2020). Emotional distress among the Bedouin Arab and Jewish elderly in Israel: the roles of gender, discrimination, and self-esteem. Psychiatry Res. 291:113203. doi: $10.1016 /$ j.psychres.2020.113203

Ahmed, M. Z., Ahmed, O., Aibao, Z., Hanbin, S., Siyu, L., and Ahmad, A. (2020). Epidemic of COVID-19 in China and associated psychological problems. Asian J. Psychiatr. 51, 1-7. doi: 10.1016/j.ajp.2020.102092

Alkhamees, A. A., Alrashed, S. A., Alzunaydi, A. A., Almohimeed, A. S., and Aljohani, M. S. (2020). The psychological impact of COVID-19 pandemic on the general population of Saudi Arabia. Compr. Psychiatry 102:152192. doi: 10.1016/j.comppsych.2020.152192

Atchison, C. J., Bowman, L., Vrinten, C., Redd, R., Pristera, P., Eaton, J. W., et al. (2020). Perceptions and behavioural responses of the general public during the COVID19 pandemic: a cross-sectional survey of UK Adults. medRxiv. 11:e043577. doi: 10.1101/2020.04.01.20050039

Babore, A., Lombardi, L., Viceconti, M. L., Pignataro, S., Marino, V., Crudele, M., et al. (2020). Psychological effects of the COVID2019 pandemic: perceived stress and coping strategies among healthcare professionals. Psychiatry Res. 293:113366. doi: 10.1016/j.psychres.2020.113366

Badahdah, A. M., Khamis, F., and Al Mahyijari, N. (2020). The psychological well-being of physicians during COVID-19 outbreak in Oman. Psychiatry Res. 289:113053. doi: 10.1016/j.psychres.2020.113053

Bao, Y., Sun, Y., Meng, S., Shi, J., and Lu, L. (2020). 2019-n CoV epidemic: address mental health care to empower society. Lancet 395, E37-E38. doi: 10.1016/S0140-6736(20)30309-3

Barahmand, U. (2008). Age and gender differences in adolescent worry. Pers. Individ. Dif. 45, 778-783. doi: 10.1016/j.paid.2008.08.006

Bilodeau, J., Marchand, A., and Lee, A. (2020). Psychological distress inequality between employed men and women: a gendered exposure model. Population Health 11:100626. doi: 10.1016/j.ssmph.2020.100626

Bottesi, G., Martignon, A., Cerea, S., and Ghisi, M. (2018). Worry and associated cognitive features in Italian university students: does gender make a difference? Pers. Individ. Dif. 126, 38-43. doi: 10.1016/j.paid.2018.01.016

Brooks, S. K., Webster, R. K., Smith, L. E., Woodland, L., Wessely, S., Greenberg, N., et al. (2020). The psychological impact of quarantine and how to reduce it: rapid review of the evidence. Lancet 395, 912-920. doi: 10.1016/S0140-6736(20)30460-8 population. Therefore, future studies may use more fine-grained analysis to obtain more comprehensive results.

\section{DATA AVAILABILITY STATEMENT}

The original contributions presented in the study are included in the article/supplementary material, further inquiries can be directed to the corresponding author/s.

\section{ETHICS STATEMENT}

The studies involving human participants were reviewed and approved by Social Sciences Research Ethics Committee, United Arab Emirates University. The patients/participants provided their written informed consent to participate in this study.

\section{AUTHOR CONTRIBUTIONS}

All authors contributed to the manuscript planning, data collection, the preparation of this conceptualization, data curation, formal analysis, investigation, methodology, project administration, resources, validation, writing the original draft, writing, review, and editing.

CDC (2020). Centers for Disease Control and Prevention (CDC) Corona Virus (COVID-19). Available online at: https://www.cdc.gov/coronavirus/2019-ncov/ symptoms-testing/index.html (accessed March, 2020).

Chodkiewicz, J., Talarowska, M., Miniszewska, J., Nawrocka, N., and Bilinski, P. (2020). Alcohol consumption reported during the COVID-19 pandemic: the initial stage. Int. J. Environ. Res. Public Health 17:4677. doi: 10.3390/ijerph17134677

Choi, Y., Moon, E., Park, J. M., Lee, B. D., Lee, Y. M., Jeong, H. J., et al. (2017). Psychometric properties of the coping inventory for stressful situations in Korean adults. Psychiatry Investig. 14, 427-433. doi: 10.4306/pi.2017.14.4.427

Cosway, R., Endler, N. S., Sadler, A. J., and Deary, I. J. (2000). The coping inventory for stressful situations: factor structure and associations with personality traits and psychological health. J. Appl. Behav. Res. 5, 121-143. doi: 10.1111/j.1751-9861.2000.tb00069.x

Czeisler, M. E., Lane, R. I., Petrosky, E., Wiley, J. F., Christensen, A., and Njai, R. (2020). Mental health, substance use, and suicidal ideation during the COVID-19 pandemic in United States. Morbid. Mortal. Wkly. Rep. 69, 24-30. doi: 10.15585/mmwr.mm6932al

Dar, K. A., Iqbal, N., and Mushtaq, A. (2017). Intolerance of uncertainty, depression, and anxiety: examining the indirect and moderating effects of worry. Asian J. Psychiatr. 29, 129-133. doi: 10.1016/j.ajp.2017.04.017

Domotor, Z., Nordin, S., Witthöft, M., and Köteles, F. (2019). Modern health worries: a systematic review. J. Psychosom. Res. 124, 2-13. doi: 10.1016/j.jpsychores.2019.109781

Endler, N. S., and Parker, J. D. (1994). Coping Inventory for Stressful Situations (CISS): Manual. Toronto, ON: Multi Health System.

Endsley, P., Weobong, B., and Nadkarni, A. (2017). The psychometric properties of GHQ for detecting common mental disorder among community dwelling men in Goa, India. Asian J. Psychiatr. 28, 106-110. doi: 10.1016/j.ajp.2017.03.023

Flannery, K. M., Vannucci, A., and Ohannessian, C. M. (2018). Using timevarying effect modeling to examine age-varying gender differences in coping throughout adolescence and emerging adulthood. J. Adolesc. Health 62, S27S34. doi: 10.1016/j.jadohealth.2017.09.027

Fu, W., Wang, C., Zou, L., Guo, Y., Lu, Z., Yan, S., et al. (2020). Psychological health, sleep quality, and coping styles to stress facing the COVID-19 in Wuhan, China. Transl. Psychiatry 10, 2-9. doi: 10.1038/s41398-02000913-3

Gemmell, L. A., Terhorst, L., Jhamb, M., Unruh, M., Myaskovsky, L., Kester, L., et al. (2016). Gender and racial differences in stress, coping, and 
health-related quality of life in chronic kidney. Pain Sympt. Manag. 52, 806-812. doi: 10.1016/j.jpainsymman.2016.05.029

Goldberg, D., and Williams, P. (1991). A User's Guide to the General Health Questionnaire. London: NferNelson.

Gravetter, F., and Wallnau, L. (2014). Essentials of Statistics for the Behavioral Sciences, 8th Edn. Wadsworth, $\mathrm{OH}$.

Guan, W.-J., Ni, Z.-Y., Hu, Y., Liang, W.-H., Ou, C.-Q., He, J.-X., et al. (2020). Clinical characteristics of coronavirus disease 2019 in China. N. Engl. J. Med. 382, 1708-1720. doi: 10.1056/NEJMoa2002032

Hamid, A. A. M., and Abdullah, S. A. (2020). Job distress and burnout among Tanzanian and Sudanese health professionals: a comparative study. South Afr. J. Psychol. 50, 411-424. doi: 10.1177/0081246319898054

Hamid, A. A. M., and Musa, S. A. (2010). Mental health problems among internally displaced persons in Darfur. Int. J. Psychol. 45, 278-285. doi: 10.1080/00207591003692620

Hamid, A. A. M., and Musa, S. A. (2017). The mediating effects of coping strategies on the relationship between secondary traumatic stress and burnout in professional caregivers in the UAE. J. Mental Health 26, 28-35. doi: 10.1080/09638237.2016.1244714

Hamid, A. A. R. M., and Abdullah, A. S. (2017). Differences in coping with stressful situations between Tanzanian and Emirati University Students. Int. J. Psychol. Behav. Anal. 1, 108-112. doi: 10.15344/2455-3867/2015/108

Hong, R. Y. (2007). Worry and rumination: differential associations with anxious and depressive symptoms and coping behavior. Behav. Res. Ther. 45, 277-290. doi: 10.1016/j.brat.2006.03.006

Hunt, S., Wisockia, P., and Yanko, J. (2003). Worry and use of coping strategies among older and younger adults. Anxiety Disorders 17, 547-560. doi: 10.1016/S0887-6185(02)00229-3

ITC (2017). Guidelines for translating and adapting tests (second edition). Int. J. Test. 18, 101-134. doi: 10.1080/15305058.2017.1398166

Kibbey, M., Fedorenko, E., and Farris, S. (2021). Anxiety, depression, and health anxiety in undergraduate students living in initial US outbreak "hotspot" during COVID-19 pandemic. Cogn. Behav. Therapy 50, 1-13. doi: 10.1080/16506073.2020.1853805

Li, X., Yu, H., Bian, G., Hu, Z., Liu, X., Zhoua, Q., et al. (2020). Prevalence, risk factors, and clinical correlates of insomnia in volunteer and at home medical staff during the COVID-19. Brain Behav. Immun. 87, 140-141. doi: 10.1016/j.bbi.2020.05.008

Lyons,. Z., Wilcox, H., Leung,. L., and Dearsley, O. (2020). COVID-19 and the mental well-being of Australian medical students: impact, concerns and coping strategies used. Aust. Psychiatry 28, 1-5. doi: 10.1177/1039856220947945

Martínez, I. M., Meneghel, I., and Penalve, J. (2019). Does gender affect coping strategies leading to well-being and improved academic performance? Rev. Psicodidáctica 2, 111-119. doi: 10.1016/j.psicoe.2019.01.002

Meyer, T. J., Miller, M. L., Metzger, R. L., and Borkovec, T. D. (1990). Development and validation of the penn state worry questionnaire. Behav. Res. Ther. 26, 487-495. doi: 10.1016/0005-7967(90)90135-6

Moghanibashi-Mansourieh., A. (2020). Assessing the anxiety level of Iranian general population during COVID-19 outbreak. Asian J. Psychiatr. 51. doi: $10.1016 /$ j.ajp.2020.102076

Mulvany, J., Hetherington, V., and VanGeest, J. (2019). Survey research in podiatric medicine: An analysis of the reporting of response rates and nonresponse bias. Foot 40, 92-97. doi: 10.1016/j.foot.2019.05.005

Olaseni, O. A., Akinsola, O. S., Agberotimi, S. F., and Oguntayo, R. (2020). Psychological distress experiences of Nigerians during Covid-19 pandemic; the gender difference. Soc. Sci. Human. 2:100052. doi: 10.1016/j.ssaho.2020.100052

Park, H. J., Kim, J. H., Lee, J. H., Heo, J. Y., and Yu, B. H. (2014). The usefulness of the Korean version of the Penn State Worry Questionnaire for screening generalized anxiety disorder: a receiver operating characteristic analysis. Psychiatry Investig. 11, 12-17. doi: 10.4306/pi.2014.11.1.12

Petzold, M., Bendau, A., Plag, J., Pyrkosch, L., Maricic, L., Betzler, F., et al. (2020). Risk, resilience, psychological distress, and anxiety at the beginning of the COVID-19 pandemic in Germany. Brain Behav. 1:10. doi: 10.1002/brb3. 1745

Rafnsson, F. D., Smari, J., Windle, M., Mears, S., and Endler, N., S. (2006). Factor structure and psychometric characteristics of the Icelandic version of the Coping Inventory for Stressful Situations (CISS). Pers. Individ. Dif. 40, 1247-1258. doi: 10.1016/j.paid.2005.11.011

$\begin{array}{cccccr}\text { Rushabh, } & \text { D. }(2020) . & \text { Fear and } & \text { anxiety-coping } & \text { strategies } \\ \text { during } & \text { COVID-19 } & \text { pandemic } & \text { in lockdown. } & \text { J. Int. }\end{array}$
Oral Health 12, 187-188. doi: 10.4103/JIOH.JIOH $133 \_20$

Sallow, B. L., Lindow, S. W., Masson, E. A., and Hay, D. M. (2003). The use of the General Health Questionnaire (GHQ-28) to estimate prevalence of psychiatric disorder in early pregnancy. Psychol. Health Med. 8, 213-217. doi: 10.1080/1354850031000087591

Shahrour, G., and Dardas, L. (2020). Acute stress disorder, coping self-efficacy and subsequent psychological distress among nurses amid COVID-19. J. Nurs. Manag. 28, 1-10. doi: 10.1111/jonm.13124

Sivo, S., Saunders, C., Chang, Q., and Jiang, J. (2006). How low should you go? Low response rates and the validity of inference in IS questionnaire research. $J$. Assoc. Inf. Syst. 7, 351-414. doi: 10.17705/1jais.00093

Son, C., Hegde, S., Smith, A., Wang, X., and Sasangohar, F. (2020). Effects of COVID-19 on college students' mental health in the United States: interview survey study. J. Med. Internet Res. 22:e21279. doi: 10.2196/21279

Umucu, E., and Lee, B. (2020). Examining the impact of COVID-19 on stress and coping strategies in individuals with disabilities and chronic conditions. Rehabil. Psychol. 65, 193-198. doi: 10.1037/rep0000328

Verity, R., Okell, L. C., and Dorigatti, I. (2020). Estimates of the severity of coronavirus disease 2019: a model-based analysis. Lancet Infect. Dis. 20, 669-677. doi: 10.1016/S1473-3099(20)30243-7

VivWuthrich, V. M., Johnco, C., and Knight, A. (2014). Comparison of the Penn State Worry Questionnaire (PSWQ) and abbreviated version (PSWQ-A) in a clinical and non-clinical population of older adults. J. Anxiety Disord. 28, 657-663. doi: 10.1016/j.janxdis.2014.07.005

Wang, C., Pan, R., Wan, X., Tan, Y., Xu, L., Cyrus, S., et al. (2020). Immediate psychological responses and associated factors during the initial stage of the 2019 coronavirus disease (COVID-19) epidemic among the general population in China. Int. J. Environ. Res. Public Health 17:1729. doi: 10.3390/ijerph17051729

WHO (2020a). Rolling Updates on Coronavirus Disease (COVID-19). Available online at: https://www.who.int/emergencies/diseases/novel-coronavirus-2019/ events-as-theyhappen (accessed July, 2020).

WHO (2020b). Available online at: http://www.euro.who.int/en/health-topics/ health-emergencies/coronavirus-COVID19/novel-coronavirus-2019-ncovtechnical-guidance/coronavirus-disease-COVID-19- outbreak-technicalguidance-europe/mental-health-and-COVID-19 (accessed July, 2020).

World Economic Forum (2020). Lockdown is the World's Biggest Psychological Experiment - and We Will Pay the Price. Available online at: https://www. weforum.org/agenda/2020/04/this-is- thepsychological-side- of-the-COVID19-pandemic-that-were-ignoring/ (accessed April, 2020).

Xiang, Y.-T., Yang, Y., Li, W., Zhang, L., Zhang, O., Cheung, T., et al. (2020). Timely mental health care for the 2019 novel coronavirus outbreak is urgently needed. Lancet Psychiatry 3, 228-229. doi: 10.1016/S2215-0366(20)30046-8

Yu, H., Li, M., Li, Z., Xiang, W., Yuan, Y., Liu, Y., et al. (2020). Coping style, social support and psychological distress in the general Chinese population in the early stages of the COVID-19 epidemic. BMC Psychiatry 20:426. doi: 10.1186/s12888-020-02826-3

Zlomke, K. R., and Hahn, K. H. (2010). Cognitive emotion regulation strategies: gender differences and associations to worry. Pers. Individ. Dif. 48, 408-413. doi: $10.1016 /$ j.paid.2009.11.007

Conflict of Interest: The authors declare that the research was conducted in the absence of any commercial or financial relationships that could be construed as a potential conflict of interest.

Publisher's Note: All claims expressed in this article are solely those of the authors and do not necessarily represent those of their affiliated organizations, or those of the publisher, the editors and the reviewers. Any product that may be evaluated in this article, or claim that may be made by its manufacturer, is not guaranteed or endorsed by the publisher.

Copyright (c) 2021 Al Miskry, Hamid and Darweesh. This is an open-access article distributed under the terms of the Creative Commons Attribution License (CC BY). The use, distribution or reproduction in other forums is permitted, provided the original author(s) and the copyright owner(s) are credited and that the original publication in this journal is cited, in accordance with accepted academic practice. No use, distribution or reproduction is permitted which does not comply with these terms. 